\title{
KARAKTERISASI SIFAT MAGNET DAN KANDUNGAN MINERAL PASIR BESI SUNGAI BATANG KURANJI PADANG SUMATERA BARAT
}

\author{
Afdal \& Lusi Niarti \\ Jurusan Fisika FMIPA Universitas Andalas \\ Kampus Unand, Limau Manis, Padang, 25163 \\ e-mail: afdal@fmipa.unand.ac.id
}

\begin{abstract}
ABSTRAK
Sifat magnet yang ditentukan pada penelitian ini adalah suseptibilitas magnetik dan kandungan mineral pasir besi. Persentase massa pasir besi yang terdapat di dalam pasir di lokasi penelitian tidak merata dengan nilai berkisar antara 5,01\% dan 20,26\%. Jumlah ini lebih kecil dibanding persentase rata-rata pasir besi dari daerah pantai Padang. Suseptibilitas magnetik pasir besi pada daerah penelitian berkisar antara $4,921 \times 10^{-5} \mathrm{~m}^{3} \mathrm{~kg}^{-1}$ dan $56,020 \times 10^{-5} \mathrm{~m}^{3} \mathrm{~kg}^{-1}$ yang masuk kelompok ferromagnetik, dan nilai cukup tinggi jika dibandingkan dengan yang diperoleh dari pasir pantai. Dari hasil pengukuran menggunakan $x$-ray diffractometer diketahui bahwa mineral yang terdapat dalam pasir besi di lokasi penelitian adalah albite $\left(\mathrm{NaAlSi}_{3} \mathrm{O}_{8}\right)$. Selain $\mathrm{itu}$, juga ditemukan mineral lain yaitu magnetite $\left(\mathrm{Fe}_{3} \mathrm{O}_{4}\right)$, quartz $\left(\mathrm{SiO}_{2}\right)$, halloysite $\left(\mathrm{Al}_{2} \mathrm{Si}_{2} \mathrm{O}_{5}(\mathrm{OH})_{4} 2 \mathrm{H}_{2} \mathrm{O}\right)$, saponite $\left(\mathrm{CaO}_{2} \mathrm{Mg} 3(\mathrm{SiAl})_{4} \mathrm{O}_{10}(\mathrm{OH})_{2} 4 \mathrm{H}_{2} \mathrm{O}\right)$ dan pyrophyllite $\left(\mathrm{Al}_{2} \mathrm{O}_{3} 4 \mathrm{SiO}_{2} \mathrm{H}_{2} \mathrm{O}\right)$.
\end{abstract}

Katakunci: pasir besi, suseptibilitas magnetik, mineral magnetik

\begin{abstract}
ABSTACT
The magnetic properties which were determined in this study is the magnetic susceptibility and iron content of iron sands. Mass percentage of iron sand in the sand at the research area is uneven with values ranging between $5.01 \%$ and $20.26 \%$. This number is smaller than average percentage of iron sand from the area of Padang beach. Magnetic susceptibility of iron sand from the research area ranged from $4,921 \times 10^{-5} \mathrm{~m}^{3} \mathrm{~kg}^{-1}$ to $56,020 \times 10^{-5} \mathrm{~m}^{3} \mathrm{~kg}^{-1}$, and this value is quite high when compared with those obtained from the sand beach. From the $\mathrm{x}$-ray diffractometer analysis is known that the mineral contained in the sand at the study site is a albite (NaAlSi3O8). In addition, other minerals also found are magnetite $\left(\mathrm{Fe}_{3} \mathrm{O}_{4}\right)$, quartz $\left(\mathrm{SiO}_{2}\right)$, halloysite $\left(\mathrm{Al}_{2} \mathrm{Si}_{2} \mathrm{O}_{5}(\mathrm{OH})_{4} 2 \mathrm{H}_{2} \mathrm{O}\right)$, saponite $\left(\mathrm{CaO}_{2} \mathrm{Mg} 3(\mathrm{SiAl})_{4} \mathrm{O}_{10}(\mathrm{OH})_{2} 4 \mathrm{H}_{2} \mathrm{O}\right)$ and pyrophyllite $\left(\mathrm{Al}_{2} \mathrm{O}_{3} 4 \mathrm{SiO}_{2}\right.$ $\mathrm{H}_{2} \mathrm{O}$ ).
\end{abstract}

Keywords: iron sand, magnetic susceptibility, magnetic mineral

\section{PENDAHULUAN}

Pasir merupakan bahan alam yang tersedia sangat melimpah di Indonesia. Selama ini pasir hanya dimanfaatkan sebagai bahan bangunan, padahal pasir banyak mengandung mineral berharga yang mengandung unsur besi, titanium dan unsur lainnya yang bisa dimanfaatkan untuk bahan industri. Di dalam pasir juga terkandung pasir besi yang dapat dimanfaatkan sebagai bahan baku pembuatan semen. Untuk menghasilkan semen berkualitas tinggi, selain batu kapur yang mengandung senyawa kalsium oksida $(\mathrm{CaO})$ dan tanah liat yang mengandung silika dioksida $\left(\mathrm{SiO}_{2}\right)$, dibutuhkan pasir besi yang mengandung unsur Fe. Endapan pasir besi dapat mengandung mineral-mineral magnetik seperti magnetit $\left(\mathrm{Fe}_{3} \mathrm{O}_{4}\right)$, hematit $\left(\alpha-\mathrm{Fe}_{2} \mathrm{O}_{3}\right)$, dan maghemit $\left(\gamma-\mathrm{Fe}_{2} \mathrm{O}_{3}\right)$. Mineral-mineral tersebut mempunyai potensi untuk dikembangkan sebagai bahan industri. Sebagai contoh, magnetit dapat digunakan 
sebagai bahan dasar untuk tinta kering (toner) pada mesin photo-copy dan printer laser, sementara maghemit adalah bahan utama untuk pita kaset. Ketiga mineral magnetik di atas dapat juga digunakan sebagai pewarna serta campuran (filler) untuk cat serta bahan dasar untuk industri magnet permanen (Yulianto dkk, 2003). Selama ini penelitian pasir besi hanya dilakukan di pantai, seperti penelitian mengenai sifat magnetik pasir besi oleh Mufit dkk (2006) di Pantai Sunur, Pariaman, Sumatera Barat dan Afdal \& Ramadhani (2011) di Pantai Air Tawar Padang Sumatera Barat. Afdal \& Ramadhani (2011) menemukan bahwa kandungan pasir besi dalam pasir yang terdapat di Pantai Air Tawar Padang cukup tinggi $(41,320 \%)$ dengan nilai suseptibilitas yang besar dan bernilai positif. Selain di pantai, pasir juga banyak terdapat di sungai-sungai. Pasir yang terdapat di pantai juga berasal dari sungai. Pasir di sungai memiliki kemiripan tampilan fisik dengan pasir pantai. Jadi, kemungkinan pasir sungai juga memiliki pasir besi dan kandungan mineral yang sama dengan pasir pantai. Kota Padang memiliki banyak sungai, yaitu lima sungai besar dan 16 sungai kecil. Batang Kandis (20 km), Batang Kuranji (17 km), Batang Logam (15 $\mathrm{km})$, Sungai Tarung $(12 \mathrm{~km})$ dan Batang Pagang $(11 \mathrm{~km})$ merupakan lima sungai terbesar di Padang. Untuk kali ini akan dilakukan penelitian di sungai Batang Kuranji. Sungai ini mempunyai panjang $17 \mathrm{~km}$ dengan lebar $39 \mathrm{~m}$. Diperkirakan sungai ini mempunyai kandungan pasir yang banyak karena terdapat banyak aktivitas penambangan pasir di sana. Untuk mengetahui potensi kandungan pasir besi dan jenis mineral yang terdapat dalam pasir di sungai Batang Kuranji perlu dilakukan penelitian ini. Hal yang akan kaji adalah kandungan pasir besi dalam pasir, nilai suseptibilitas magnetik dan kandungan mineral dalam pasir besi. Dengan diketahuinya kandungan mineral dan karakteristik magnetik yang terdapat pada pasir besi ini, maka dapat dikaji potensi teknis dan ekonomisnya untuk dapat dimanfaatkan untuk berbagai keperluan.

\section{METODOLOGI}

\section{Waktu \& Lokasi Penelitian}

Penelitian ini dilaksanakan dari September 2011 sampai Januari 2012 di Laboratorium Fisika Bumi, Jurusan Fisika, Universitas Andalas. Daerah penelitian adalah penambangan pasir yang terdapat di sepanjang sungai Batang Kuranji, Padang, Sumatera Barat.

\section{Peralatan}

Peralatan utama yang digunakan dalam penelitian ini adalah magnetic susceptibility meter (Bartington magnetic susceptibility sensor model MS2 dengan dual frequency sensor model MS2B), XRD, dan magnet permanen.

\section{Pengumpulan Sampel}

Sampel pasir diambil di tiga lokasi penambangan pasir yaitu Kuranji, Siteba I, dan Siteba II. Untuk setiap lokasi penambangan, sampel pasir diambil pada dua lintasan (satu lintasan di dalam sungai (lintasan I), dan satu lintasan di pinggir sungai (lintasan II)) dengan jarak antar lintasan adalah $7 \mathrm{~m}$. Untuk masing-masing lintasan, sampel diambil pada lima titik dengan jarak antar titik adalah 10 meter. Pada setiap titik, sampel pasir diambil sebanyak $100 \mathrm{~g}$.

\section{Pegukuran Kandungan Pasir Besi}

Untuk setiap sampel pasir yang diambil yaitu masing-masing sebanyak $100 \mathrm{~g}$ dilakukan pemisahan pasir besi dari sampel pasir dengan magnet permanen. Setelah dipisahkan, selanjutnya ditentukan massa pasir besi yang diperoleh. Hal ini dilakukan untuk semua sampel. 


\section{Penentuan Nilai Suseptibilitas Massa}

Setelah massa pasir besi dari masing-masing lokasi ditentukan, selanjutnya dilakukan pengukuran suseptibilitas magnet pasir besi dari setiap titik lokasi menggunakan magnetic susceptibility meter. Untuk setiap titik sampel digunakan jumlah massa yang sama yaitu 5,0 g.

\section{Penentuan Kandungan Mineral dalam Pasir Besi}

Tahap selanjutnya adalah penentuan mineral yang terkandung dalam pasir besi menggunakan $x$-ray difractometer $(X R D)$, yang dilakukan di Laboratorium Teknik Pertambangan ITB.

\section{HASIL DAN DISKUSI}

Pembahasan yang dilakukan adalah kandungan pasir besi dalam pasir dan suseptibilitas magnetik pasir besinya.

\section{Persentase Pasir Besi dalam Pasir Sungai}

Persentase massa pasir besi dalam pasir di sungai Batang Kuranji untuk ketiga lokasi penambangan dapat dilihat pada Tabel 1 sampai 3. Dari Tabel 1 dapat dilihat bahwa persentase massa pasir besi pada penambangan A adalah 19,34\% - 21,40\% untuk Lintasan I (di dalam sungai) dan 17,15\% - 18,48\% untuk Lintasan II (di pinggir sungai). Dapat dilihat bahwa persentase massa pasir besi yang terdapat di pinggir dan di dalam sungai hampir sama. Untuk penambangan Kuranji, kandungan pasir besi sangat bervariasi dengan nilai rata-ratanya adalah $19,420 \%$.

\begin{tabular}{|c|c|c|c|c|c|}
\hline \multirow{2}{*}{ Titik Lokasi } & \multirow{2}{*}{$\begin{array}{c}\text { Nama } \\
\text { Sampel }\end{array}$} & \multicolumn{3}{|c|}{ Massa (g) / Pengukuran ke- } & \multirow{2}{*}{$\begin{array}{c}\% \text { massa } \\
\text { rata-rata }\end{array}$} \\
\hline & & 1 & 2 & 3 & \\
\hline \multirow{5}{*}{ Lintasan I } & A11 & 20,02 & 20,01 & 20,02 & 20,02 \\
\hline & $\mathrm{A} 12$ & 19,33 & 19,34 & 19,34 & 19,34 \\
\hline & A13 & 19,98 & 19,96 & 19,95 & 19,96 \\
\hline & A14 & 21,41 & 21,39 & 21,40 & 21,40 \\
\hline & A15 & 20,27 & 20,25 & 20,27 & 20,26 \\
\hline \multirow{5}{*}{ Lintasan II } & A21 & 19,37 & 19,35 & 19,36 & 19,36 \\
\hline & A22 & 17,14 & 17,16 & 17,16 & 17,15 \\
\hline & A23 & 18,49 & 18,48 & 28,48 & 18,48 \\
\hline & A24 & 19,18 & 19,15 & 19,15 & 19,16 \\
\hline & A25 & 19,06 & 19,09 & 19,08 & 19,07 \\
\hline \multicolumn{5}{|c|}{ Rata-rata total } & 19,42 \\
\hline
\end{tabular}

Tabel 2 menampilkan persentase massa pasir besi pada penambangan Siteba I. Dari Tabel 2 dapat dilihat bahwa persentase massa pasir besi di penambangan Siteba I ini lebih kecil dibandingkan dengan penambangan Kuranji, yaitu pada Lintasan I antara 8,41\% 10,74\%, dan pada Lintasan II antara 5,01\% - 7,46\%. Jadi, pada lokasi ini persentase rata-ratanya adalah $7,85 \%$. 


\begin{tabular}{|c|c|c|c|c|c|}
\hline \multicolumn{6}{|c|}{$\begin{array}{l}\text { Tabel } 2 \text { Persentase massa pasir besi di penambangan Siteba I, Sungai Batang } \\
\text { Kuranji, Padang }\end{array}$} \\
\hline \multirow{2}{*}{ Titik Lokasi } & \multirow{2}{*}{$\begin{array}{c}\text { Nama Sampel } \\
\text { Pasir }\end{array}$} & \multicolumn{3}{|c|}{ Massa (g) / Pengukuran ke- } & \multirow{2}{*}{$\begin{array}{l}\% \text { massa } \\
\text { rata-rata }\end{array}$} \\
\hline & & 1 & 2 & 3 & \\
\hline \multirow{5}{*}{ Lintasan I } & B11 & 10,73 & 10,75 & 10,75 & 10,74 \\
\hline & B12 & 10,08 & 10,08 & 10,07 & 10,08 \\
\hline & B13 & 8,43 & 8,40 & 8,41 & 8,41 \\
\hline & B14 & 9,61 & 9,63 & 9,62 & 9,62 \\
\hline & B15 & 8,86 & 8,84 & 8,85 & 8,85 \\
\hline \multirow{5}{*}{ Lintasan II } & $\mathrm{B} 21$ & 7,03 & 7,02 & 7,01 & 7,02 \\
\hline & B22 & 6,94 & 6,92 & 6,93 & 6,93 \\
\hline & B23 & 5,01 & 5,02 & 5,01 & 5,01 \\
\hline & B24 & 7,46 & 7,47 & 7,46 & 7,46 \\
\hline & $\mathrm{B} 25$ & 7,31 & 7,29 & 7,30 & 7,30 \\
\hline \multicolumn{5}{|c|}{ Rata-rata total } & 7,85 \\
\hline
\end{tabular}

Dari Tabel 3 dapat dilihat persentase massa pasir besi pada penambangan Siteba II. Pada Lintasan I persentase massanya adalah $16,77 \%$ - 20,19\%. Sedangkan pada Lintasan II adalah $16,87 \%$ - 18,71\%. Untuk penambangan C, kandungan pasir besi tidak terlalu bervariasi dengan nilai rata-ratanya adalah $8,14 \%$.

\begin{tabular}{|c|c|c|c|c|c|}
\hline \multicolumn{6}{|c|}{$\begin{array}{l}\text { Tabel } 3 \text { Persentase massa pasir besi di penambangan Siteba II (C) } \\
\text { Sungai Batang Kuranji, Padang }\end{array}$} \\
\hline \multirow{2}{*}{ Lokasi } & \multirow{2}{*}{$\begin{array}{l}\text { Narna Sampel } \\
\quad \text { Pasir }\end{array}$} & \multicolumn{3}{|c|}{ Massa (g) / Pengukuran ke- } & \multirow{2}{*}{$\begin{array}{l}\% \text { massa } \\
\text { rata-rata }\end{array}$} \\
\hline & & 1 & 2 & 3 & \\
\hline & & 16,78 & 16,76 & 16,77 & 16,77 \\
\hline & $\mathrm{C} 12$ & 18,41 & 18,40 & 18,40 & 18,40 \\
\hline & $\mathrm{C} 13$ & 19,16 & 19,14 & 19,14 & 19,15 \\
\hline & $\mathrm{C} 14$ & 19,69 & 19,67 & 19,68 & 19,68 \\
\hline & $\mathrm{C} 15$ & 20,20 & 20,18 & 20,19 & 20,19 \\
\hline \multirow{5}{*}{ Lintasan II } & $\mathrm{C} 21$ & 17,18 & 17,15 & 17,15 & 17,16 \\
\hline & $\mathrm{C} 22$ & 17,43 & 17,40 & 17,43 & 17,42 \\
\hline & $\mathrm{C} 23$ & 16,89 & 16,85 & 16,86 & 16,87 \\
\hline & $\mathrm{C} 24$ & 18,73 & 18,70 & 18,71 & 18,71 \\
\hline & $\mathrm{C} 25$ & 17,04 & 17,02 & 17,01 & 17,02 \\
\hline \multicolumn{5}{|c|}{ Rata-rata total } & 18,14 \\
\hline
\end{tabular}

Dari Tabel 1 sampai Tabel 3 dapat dilihat bahwa persentase rata-rata massa pasir besi pada penambangan Kuranji dan Siteba II hampir sama yaitu sekitar 19\%, sedangkan pada penambangan Siteba I persentase rata-rata massa pasir besinya lebih kecil yaitu 7,85\%. Untuk ketiga lokasi, persentase pasir besi di luar sungai tidak jauh berbeda dibandingkan dengan di dalam sungai. Untuk ketiga lokasi persentase rata-rata massa pasir besi di sungai Batang Kuranji adalah 15,137 \%. Jumlah ini lebih kecil daripada rata-rata 
persentase massa pasir besi dalam pasir pantai Padang yaitu 41,320 \% (Afdal dan Ramadhani, 2012), tapi lebih besar dibandingkan di daerah muara sungai Cimanuk (pantai Waledan) dengan rata-rata 13,004 \% (Sunaryo dan Sugihartono, 2010).

\section{Suseptibilitas Magnetik Pasir Besi}

Hasil pengukuran suseptibilitas magnetik pasir besi yang terdapat di Sungai Batang Kuranji, Padang, Sumatera Barat dapat dilihat pada Tabel 4, 5 dan 6. Dari Tabel 4 dapat dilihat bahwa suseptibilitas magnetik pasir besi pada penambangan Kuranji di Lintasan I adalah $14,6525 \times 10^{-5} \mathrm{~m}^{3} \mathrm{~kg}^{-1}-54,8912 \times 10^{-5} \mathrm{~m}^{3} \mathrm{~kg}^{-1}$ dan untuk Lintasan II adalah $4,9211 \times 10^{-5} \mathrm{~m}^{3} \mathrm{~kg}^{-1}-55,7346 \times 10^{-5} \mathrm{~m}^{3} \mathrm{~kg}^{-1}$.

Tabel 4 Suseptibilitas magnetik pasir besi pada penambangan Kuranji

\begin{tabular}{|c|c|c|}
\hline Titik Lokasi & Nama Sampel & $\begin{array}{c}\text { Suseptibilitas magnetik } \\
\left(10^{-5} \mathrm{~m}^{3} \mathrm{~kg}^{-1}\right)\end{array}$ \\
\hline \multirow{4}{*}{ Lintasan I } & $\mathrm{A} 11$ & 49,9618 \\
\cline { 2 - 3 } & $\mathrm{A} 12$ & 14,6525 \\
\cline { 2 - 3 } & $\mathrm{A} 13$ & 54,8912 \\
\cline { 2 - 3 } & $\mathrm{A} 14$ & 43,9945 \\
\cline { 2 - 3 } & $\mathrm{A} 15$ & 43,9194 \\
\hline \multirow{4}{*}{ Lintasan II } & $\mathrm{A} 21$ & 9,6189 \\
\cline { 2 - 3 } & $\mathrm{A} 22$ & 55,7346 \\
\cline { 2 - 3 } & $\mathrm{A} 23$ & 4,9211 \\
\cline { 2 - 3 } & $\mathrm{A} 24$ & 39,8763 \\
\cline { 2 - 3 } & $\mathrm{A} 25$ & 51,6830 \\
\hline
\end{tabular}

\begin{tabular}{|c|c|c|}
\hline \multicolumn{2}{|c|}{$\begin{array}{c}\text { Tabel } 5 \text { Suseptibilitas magnetik pasir besi } \\
\text { pada penambangan Siteba I }\end{array}$} \\
\hline \multirow{3}{*}{ Titik Lokasi } & Nama Sampel & $\begin{array}{c}\text { Suseptibilitas magnetik } \\
\left(10^{-5} \mathrm{~m}^{3} \mathrm{~kg}^{-1}\right)\end{array}$ \\
\hline \multirow{5}{*}{ Lintasan I } & B11 & 53,0482 \\
\cline { 2 - 3 } & B12 & 52,8182 \\
\cline { 2 - 3 } & B13 & 53,2082 \\
\cline { 2 - 3 } & B14 & 46,5963 \\
\cline { 2 - 3 } & B15 & 52,5602 \\
\hline \multirow{5}{*}{ Lintasan II } & B21 & 56,0200 \\
\cline { 2 - 3 } & B22 & 36,6642 \\
\cline { 2 - 3 } & B23 & 52,8956 \\
\cline { 2 - 3 } & B24 & 53,1441 \\
\cline { 2 - 3 } & B25 & 26,0888 \\
\hline
\end{tabular}


Tabel 5 menampilkan suseptibilitas magnetik pasir besi untuk penambangan Siteba I dan grafiknya dapat dilihat pada Gambar 2. Dari Tabel 5 dapat dilihat bahwa suseptibilitas untuk masing-masing titik pada Lintasan I adalah $46,5963 \times 10^{-5} \mathrm{~m}^{3} \mathrm{~kg}^{-1}-53,2082$ $\times 10^{-5} \mathrm{~m}^{3} \mathrm{~kg}^{-1}$ sedangkan untuk Lintasan II adalah $26,0888 \times 10^{-5} \mathrm{~m}^{3} \mathrm{~kg}^{-1}-56,0200 \times 10^{-5}$ $\mathrm{m}^{3} \mathrm{~kg}^{-1}$. Dapat dilihat bahwa untuk beberapa titik Lintasan I dan II nilai suseptibilitasnya hampir sama.

Tabel 6 menunjukkan suseptibilitas magnetik pasir besi untuk penambangan Siteba II, dimana pada Lintasan I suseptibilitas magnetik masing-masing sampel adalah 44,5161 x $10^{-5} \mathrm{~m}^{3} \mathrm{~kg}^{-1}-53,2752 \times 10^{-5} \mathrm{~m}^{3} \mathrm{~kg}^{-1}$ dan Lintasan II antara $33,2011 \times 10^{-5} \mathrm{~m}^{3} \mathrm{~kg}^{-1}$ dan $48,5198 \times 10^{-5} \mathrm{~m}^{3} \mathrm{~kg}^{-1}$. Untuk Lintasan I dan II dapat dilihat bahwa nilai suseptibilitas magnetiknya hampir merata dan tidak terlalu berbeda.

\begin{tabular}{|c|c|c|}
\hline \multicolumn{3}{|c|}{ Tabel 6 Suseptibilitas pasir besi pada penambangan Siteba II } \\
\hline \multirow{4}{*}{ Titik Lokasi } & Nama Sampel & $\begin{array}{c}\text { Suseptibilitas magnetik } \\
\left(10^{-5} \mathrm{~m}^{3} \mathrm{~kg}^{-1}\right)\end{array}$ \\
\hline \multirow{4}{*}{ Lintasan I } & $\mathrm{C} 11$ & 44,7724 \\
\cline { 2 - 3 } & $\mathrm{C} 12$ & 48,4367 \\
\cline { 2 - 3 } & $\mathrm{C} 13$ & 44,5161 \\
\cline { 2 - 3 } & $\mathrm{C} 14$ & 50,4676 \\
\cline { 2 - 3 } & $\mathrm{C} 15$ & 53,2752 \\
\hline \multirow{4}{*}{ Lintasan I } & $\mathrm{C} 21$ & 55,7273 \\
\cline { 2 - 3 } & $\mathrm{C} 22$ & 48,0044 \\
\cline { 2 - 3 } & $\mathrm{C} 23$ & 48,7170 \\
\cline { 2 - 3 } & $\mathrm{C} 24$ & 33,2011 \\
\cline { 2 - 3 } & $\mathrm{C} 25$ & 48,5198 \\
\hline
\end{tabular}

Nilai suseptibilitas magnetik sampel pasir besi pada penambangan Kuranji, Siteba I, dan Siteba II di sungai Batang Kuranji, Padang, Sumatera Barat berkisar antara 4,9211 $\times 10^{-5}$ $\mathrm{m}^{3} \mathrm{~kg}^{-1}$ s.d. $56,0200 \times 10^{-5} \mathrm{~m}^{3} \mathrm{~kg}^{-1}$. Nilai ini lebih besar daripada pasir besi yang diperoleh dari pinggir pantai Padang yaitu $1,4691 \times 10^{-5} \mathrm{~m}^{3} \mathrm{~kg}^{-1}$ s.d $2,6187 \times 10^{-5} \mathrm{~m}^{3} \mathrm{~kg}^{-1}$ (Afdal dan Ramadhani, 2012). Berdasarkan nilai suseptibilitasnya, pasir besi pada ketiga penambangan termasuk dalam kelompok mineral feromagnetik, yaitu bahan yang mempunyai harga suseptibilitas magnetik yang positif dan besar $(\chi>0)$.

Perbandingan nilai suseptibilitas magnetik sampel pasir besi antar lokasi penambangan Kuranji, Siteba I dan Siteba II di dalam sungai (Lintasan I) hampir sama. Sejauh ini, nilai suseptibilitas magnetik sampel pasir besi yang paling tinggi adalah yang berasal dari penambangan Siteba I, tetapi tidak terlihat hubungan dengan jarak dari hulu sungai.

\section{Kandungan Mineral}

Untuk melihat atau mengetahui kandungan mineral yang terdapat pada pasir besi dilakukan karakterisasi menggunakan XRD yang dilakukan di Laboratorium Teknik Pertambangan ITB. Hasil XRD menunjukkan bahwa mineral utama penyusun pasir besi di lokasi penelitian adalah albite $\left(\mathrm{NaAlSi}_{3} \mathrm{O}_{8}\right)$. Pada pasir besi dari penambangan Kuranji juga ditemukan mineral lain seperti magnetite $\left(\mathrm{Fe}_{3} \mathrm{O}_{4}\right)$, quartz $\left(\mathrm{SiO}_{2}\right), \quad$ halloysite $\quad\left(\mathrm{Al}_{2} \mathrm{Si}_{2} \mathrm{O}_{5}(\mathrm{OH})_{4} \quad 2 \mathrm{H}_{2} \mathrm{O}\right), \quad$ saponite $\left(\mathrm{CaO}_{2} \mathrm{Mg} 3(\mathrm{SiAl})_{4} \mathrm{O}_{10}(\mathrm{OH})_{2} 4 \mathrm{H}_{2} \mathrm{O}\right)$ dan pyrophyllite $\left(\mathrm{Al}_{2} \mathrm{O}_{3} 4 \mathrm{SiO}_{2} \mathrm{H}_{2} \mathrm{O}\right)$. Pada pasir besi dari penambangan Siteba I dan Siteba II tidak ditemukan mineral saponite. 


\section{KESIMPULAN}

Dari penelitian ini dapat disimpulkan:

1. Pasir besi pada penambangan yang terdapat di Kuranji mempunyai rata-rata persentase massa sebesar $19,420 \%$, penambangan Siteba I dengan rata-rata persentase massa $7,853 \%$, dan penambangan Siteba II mempunyai rata-rata persentase massa $18,137 \%$. Berdasarkan nilai rata-rata pasir besi yang terdapat di tiga penambangan tersebut diketahui bahwa sebaran pasir besi tidak merata, tetapi jumlah ini lebih kecil dibanding persentase rata-rata pasir besi dari daerah pantai.

2. Berdasarkan nilai suseptibilitasnya, pasir besi di sungai Batang Kuranji termasuk dalam kelompok mineral ferromagnetik, yaitu bahan yang mempunyai harga suseptibilitas magnetik yang positif dan besar. Nilai suseptibilitas massa pasir besi tersebut cukup tinggi jika dibandingkan dengan yang diperoleh dari pasir pantai.

3. Mineral utama penyusun pasir besi di sungai Batang Kuranji, Padang, Sumatera Barat adalah albite $\left(\mathrm{NaAlSi}_{3} \mathrm{O}_{8}\right)$. Selain itu, juga ditemukan mineral lain yaitu magnetite $\left(\mathrm{Fe}_{3} \mathrm{O}_{4}\right)$, quartz $\left(\mathrm{SiO}_{2}\right)$, halloysite $\left(\mathrm{Al}_{2} \mathrm{Si}_{2} \mathrm{O}_{5}(\mathrm{OH})_{4}\right.$ $\left.2 \mathrm{H}_{2} \mathrm{O}\right)$, saponite $\left(\mathrm{CaO}_{2} \mathrm{Mg} 3(\mathrm{SiAl})_{4} \mathrm{O}_{10}(\mathrm{OH})_{2} 4 \mathrm{H}_{2} \mathrm{O}\right)$ dan pyrophyllite $\left(\mathrm{Al}_{2} \mathrm{O}_{3} \quad 4 \mathrm{SiO}_{2}\right.$ $\mathrm{H}_{2} \mathrm{O}$ ).

\section{DAFTAR PUSTAKA}

1. Afdal, Ramadhani, G, 2012, Karakterisasi Sifat Magnetik Pasir Besi Pantai Padang, Sumatera Barat, Prosiding Seminar \& Rapat Tahunan BKS-PTN B, FMIPA Universitas Negeri Medan, Medan.

2. Billmeyer, F. W., 1962, Textbook of Polymer Science, Canada.

3. Dunlop, D., O. Ozdemir, 1997, Rock Magnetic, Cambridge University Press, cambridge.

4. Jahidin, dkk, 2009), Karakterisasi Mineral Magnetik Pasir Besi Dari Tapunggaya, Sulawesi Tenggara, Jurnal Aplikasi Fisika Vol.5 No.1

5. Mufit F, Fadhillah, Bijaksana. S, 2006, Kajian Tentang Sifat Magnetik Pasir Besi dari Pantai Sunur, Pariaman, Sumatera Barat, Jurnal Geofisika.

6. Sunaryo, Sugihartono, I., 2010, Pemisahan Senyawa Titanomagnetite Fe3xTixO4 ji3O4(o,x,j) Dari Pasir Alam Indramayu, Jawa Barat, Makara, Teknologi, Vol. 14, No. 2.

7. Yulianto A., Bijaksana, S., Loeksmato, W., 2002, Karakterisasi Magnetik dari Pasir Besi Cilacap, Jurnal Fisika Himpunan Fisika Indonesia Vol. A5 No. 0527

8. Yulianto A., Bijaksana S., Loeksmanto W., 2003, Comparative Study on Magnetic Characterization of Iron Sand from Several Locations in Central Java, Kontribusi Fisika Indonesia, Vol. 14 No.2. 